and discovered that he had sought treatment for tinnitus in a local hospital. Mounting frustration because of comprehension difficulties led to the patient being transferred to a psychiatric unit. His attempts to escape from the psychiatric ward led to certification and thus he was transferred to our unit. The patient had wax syringed from his ears, and was then discharged.

This case demonstrates that English may well be a foreign language for some of our patients. The consequences of poor communication in this case are obvious, and could have been even more serious. It is exciting to hear of educational programmes in this area and one would hope that this will improve the lot of both patients and staff alike. Any attempts to reduce the incidences of miscommunication must be applauded, as the patient is the one most likely to suffer from such misunderstandings.

Alan Byrne

T. ZIBIN

Psychiatric Treatment Centre

M. FARRELLY

Alberta Hospital Ponoka

Box 1000

Ponoka, Alberta, Canada

TOC $2 \mathrm{HO}$

\section{Importance of academic medicine}

\section{DeAR SiRs}

I was delighted to see that the BMA Council is campaigning to meet the Prime Minister to discuss the health service. If that discussion takes place (as it should) I hope Council representatives will have the problems of medical schools, university funding, and medical academics high on the agenda. Everyone in the profession realises that British health depends as much on academic medicine as it does on the NHS. It is very important that that message is conveyed to the Prime Minister who uniquely has influence over both of the government departments concerned.

Institute of Psychiatry

JOHN GuNN

De Crespigny Park

London SE5 8AF
National agreement on the rotation of junior and senior trainees

\section{DeAR Sirs}

Most rotational training schemes for junior as well as senior trainees involve the move from one post to another on 1 February, 1 March, 1 August and 1 September. More often than not, these dates fall midweek so that there is a sense of abruptness and incompleteness, and loose ends are often not properly tied up before the doctor moves on.

I would like to propose that the rotation of trainees on the first Monday in February, March, August and September to enable a more natural transition from one job to another, and give the trainees the benefit of a weekend to 'clear their heads' before joining a new service.

I. O. Azuonye

The London Hospital (St Clement's)

London E3 $4 L L$

\section{Need for motoring skills for career in psychiatry}

DeAr Sirs

My congratulations to the College's Public Education Committee on their production of the career information pack for potential trainee psychiatrists.

I am employed by Trent Regional Health Authority as a senior registrar based in Nottingham. I have recently calculated that my travel expense claims for journeys performed in fulfilment of my contractual duties in the last 18 months have totalled in excess of 24,000 miles.

In this age of community psychiatry and regional registrar rotations, perhaps qualities such as an interest in motoring and car maintenance and superior navigational skills should be added to those desirable in individuals interested in pursuing a career in this branch of medicine.

Rampton Hospital

E. SUSAN LISTER 